\section{Calf Haematoma: A New Sign in Differential Diagnosis from Deep Vein Thrombosis}

\author{
D. A. TIBBUTT, A. J. GUNNING
}

British Medical fournal, 1974, 4, 204

Haemorrhage into the calf may produce symptoms and signs that mimic those of deep vein thrombosis. We have now observed four patients who illustrated this, but they showed a sign not previously described-a crescentic area of bruising around the malleoli-which we believe to be of value in the differential diagnosis.

\section{Case Reports}

Case 1.-A 77-year-old woman was admitted complaining that her left calf had been swollen for three weeks. The left lower leg was $4 \mathrm{~cm}$ greater in circumference than the right and the calf was moderately tender with a trace of pitting oedema at the ankle. An ascending venogram showed nothing abnormal, but in spite of this the patient was treated with heparin. Twelve hours later the calf had increased greatly in size, was tense, and very painful. Crescents of bruising below the malleoli were noted. The anticoagulation was discontinued and the limb slowly improved over the next four weeks.

Case 2.-A 40-year-old nurse who had had varicose veins stripped from both legs four years previously was admitted to hospital complaining of a pain of sudden onset in the calf of her left leg associated with the appearance of a lump in the lower medial aspect. Twelve hours later bruising appeared around and, especially, below the medial malleolus. The calf was moderately tender and her ankle was slightly oedematous. A venogram showed nothing abnormal. Anticoagulants were not given and the symptoms cleared rapidly.

Case 3.-A 41-year-old student had been kicked in the left calf three weeks previously, and it became swollen. The swelling cleared within two weeks but reappeared a week later. On admission to hospital there was moderate oedema of the left ankle with exquisite tenderness of the calf, which was warmer than the right calf. A crescent of bruising was present just below the medial malleolus. A venogram showed nothing abnormal. No anticoagulants were given and the symptoms and signs cleared rapidly.

Case 4.-A 46-year-old man had sustained a mild injury to the calf of the left leg from a bicycle pedal. The left lower leg became swollen and three weeks later he was referred by his family doctor because a venous thrombosis was suspected. There was moderate oedema of the ankle and marked calf tenderness. Crescents of bruising were apparent below the left medial (fig. 1) and lateral malleoli (fig. 2). A venogram showed nothing abnormal. No specific treatment was given and the limb was normal two weeks later.

Three further patients were referred to us with provisional diagnoses of deep vein thrombosis. All had had recent blunt ininjuries to the calf. Venograms showed nothing abnormal, and the symptoms and signs cleared without anticoagulation. In none of these patients did bruising appear around the ankles.

\section{Comment}

The accuracy of the clinical diagnosis of deep vein thrombosis from the physical signs has been quoted variously from $28 \%$ (Lambie et al., 1970) to $49 \%$ (Haeger, 1965) and 53\% (Nicojaides et al., 1971). Clearly, more helpful and differentiating

Radclifie Infirmary, Oxford

D. A. TIBBUTT, B.M., M.R.C.P., Senior Medical Registrar

A. J. GUNNING, F.R.C.S., Consultant Surgeon

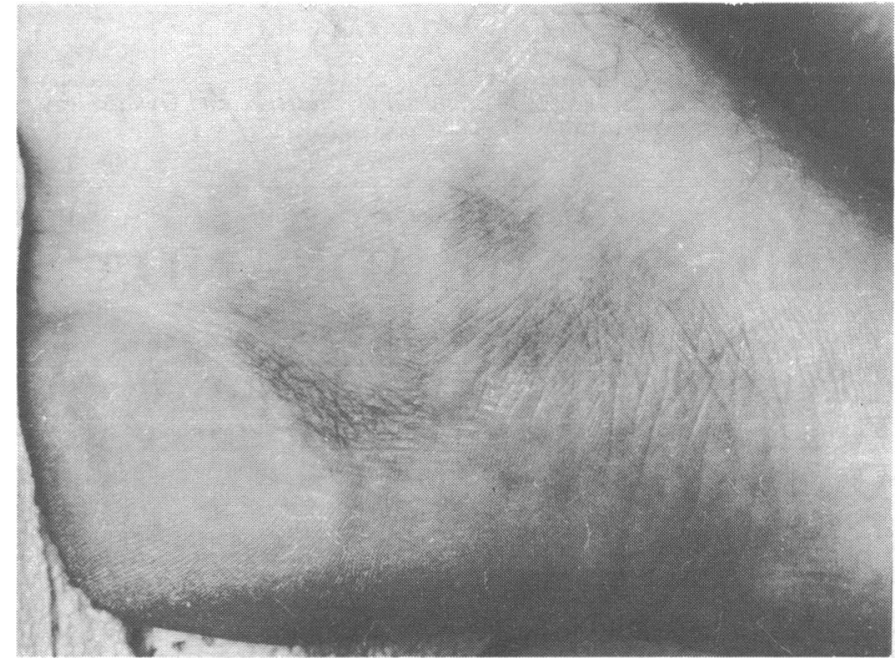

FIG. 1-Case 4. Bruising around medial malleolus.

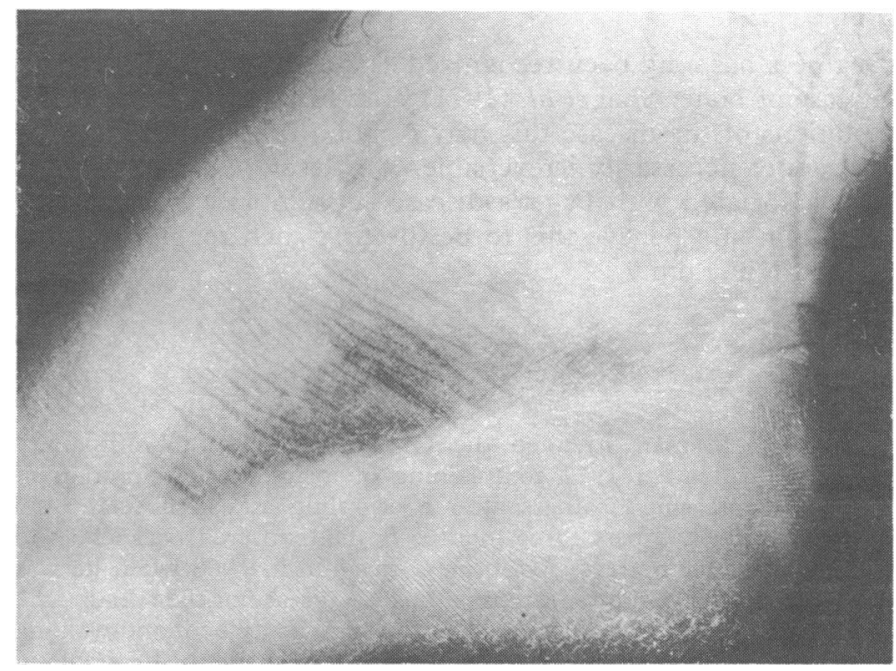

FIG. 2-Case 4. Bruising below lateral malleolus.

signs would be welcomed. Haeger et al. (1967) have enumerated the diagnoses of 23 cases presenting with a clinically suspected deep vein thrombosis but in whom venograms showed nothing abnormal, and of these six had calf haematomata.

Fluid, including blood, in the calf muscles would tend to gravitate towards the ankle if the patient remained in the erect posture and it is therefore possible that echymosis from a calf haematoma may appear in the region of the ankle. We are not aware of any previous recognition of the appearance of a crescent of bruising just below a malleolus as a sign of bleeding into the calf, which in cases 2,3 , and 4 was useful as a warning sign of this possibility. (Case 1 illustrated the likely consequences of disregarding the venographic appearances in such cases: here the "erescent sign" did not appear until after anticoagulation had begun.)

We suggest that this crescent sign is a useful pointer to an intramuscular haemorrhage, especially if the venogram shows nothing abnormal, and its recognition may avert the morbidity of inappropriate anticoagulation.

\section{References}

Haeger, K. (1965). Läkartidningen, 64, 1067.

Haeger, K., Nilsson, I. M., and Robertson, B. R. (1967). Läkartidningen, $64,3498$.

Lambie, J. M. (1970). British Medical fournal, 2, 142.

Nicolaides, A. N., et al. (1971). British fournal of Radiology, 44, 653. 